\title{
"MELHOR PIOR": SOBRE A TRADUÇÃO DE COMPANY E WORSTWARD HO DE SAMUEL BECKETT
}

\author{
Ana Helena Barbosa Bezerra de Souza* \\ Universidade Federal de Pernambuco
}

\begin{abstract}
Resumo: A tradução dos textos tardios de Samuel Beckett, Companhia (1980) e Worstward Ho (1983), suscitou reflexões e, quando de sua publicação, críticas, que serão comentadas neste artigo. Vão ser abordadas não só a justificativa de escolhas de tradução, mas a análise do que, na leitura dos textos e na consideração do português do Brasil, levou a tais escolhas. Referências a outras traduções dos mesmos textos - a francesa, a portuguesa e a italiana - aparecerão em comentários específicos. Nosso objetivo é destacar a complexidade e beleza desses textos beckettianos, do ponto de vista de um trabalho feito numa proximidade tão grande deles, como o trabalho de tradução.
\end{abstract}

Palavras-chave: Tradução. Samuel Beckett. Recepção crítica.

\section{"BETTER WORSE": ON THE TRANSLATION OF COMPANY AND WORSTWARD HO BY SAMUEL BECKETT}

\begin{abstract}
The translation of Samuel Beckett's late texts, Company (1980) and Worstward Ho (1983), gave rise to reflections and, when published, to criticism, which will be commented on in this article. Not only shall the justification of translation choices be approached, but also the analysis of what, in the reading of the texts and the consideration of Brazilian
\end{abstract}

\footnotetext{
* Ana Helena Souza, graduação em Letras, Universidade Federal de Pernambuco. Mestrado e Doutorado em Teoria Literária e Literatura Comparada, Universidade de São Paulo. Pós-Doutorado em Estudos da Tradução, Universidade Federal de Santa Catarina. É pesquisadora independente e tradutora. Belo Horizonte, Minas Gerais, Brasil. email: ahelenasouza@ gmail.com
} 
Portuguese, led to such choices. References to other translations of the same texts - the French, the Portuguese, and the Italian - will be made. Our aim is to emphasize the complexity and beauty of theses Beckettian texts from the point of view of a work carried out so close to them, as a translation work.

Keywords: Translation. Samuel Beckett. Critical reception.

\section{Nota introdutória}

Durante a tradução dos textos de Samuel Beckett que integram o volume Companhia e outros textos (BECKETT, 2012), fiz algumas anotações sobre a obra de Beckett, sobre a tradução de seus textos autotraduzidos ou, no caso de Worstward Ho, não - sobre o processo de traduzir intensamente um mesmo autor e sobre o papel do tradutor nesse processo. Os comentários abaixo limitam-se à tradução de dois dos textos do volume: Company, que dá título à coletânea, e Worstward Ho. Não pretendem cobrir nem desenvolver todos os tópicos anotados, mas apenas oferecer uma amostra, ainda que elaborada a posteriori, de como o tradutor lida com seus conhecimentos prévios sobre autor e obra, aos quais se acrescentam o que aprende e o que faz ao longo do trabalho de tradução. Nessa etapa, entram em jogo simultaneamente interpretações, análises, leituras diversas, comparações e uma obsessiva convivência com o texto-fonte.

Depois de publicada a tradução, as observações críticas por ela suscitadas passam a integrar as reflexões do tradutor. É importante ressaltar, no entanto, que numa tradução como a desses textos de Samuel Beckett, em que a reflexão sobre o processo tradutório é constante, a maior parte de tais observações críticas já surgira como problema durante o trabalho. $\mathrm{O}$ olhar crítico externo aceita ou rechaça determinadas escolhas do tradutor, baseando-se no seu conhecimento do texto original. No caso de Beckett, muitas vezes na leitura de um só dos textos da obra bilíngue do autor, ou o inglês ou o francês. $\mathrm{O}$ olhar do tradutor-leitor, que também pesquisa a obra do escritor e a ela dedica textos de crítica literá- 
ria, é forçosamente mais abrangente, incluindo o conhecimento da inteireza e dos detalhes do texto original - no caso de Company/ Compagnie, dos originais -, bem como o da inteireza e dos detalhes de sua tradução. Algumas vezes tal conhecimento facilita as opções do tradutor, outras vezes acrescenta nuances que tornam a tradução ainda mais delicada.

Como se sabe, há um limite para a justificação das escolhas do tradutor. Vale a pena indicar algumas delas para que o leitor se torne também consciente de que não se trata de traduções apressadas ou impensadas. Sempre pode haver variantes mais bem sucedidas. Tudo o que os tradutores podem empenhar-se em fazer é diminuir a margem dessas variantes.

\section{A prosa de Beckett e sua tradução, autotradução, bilinguismo}

A riqueza e a variedade da obra de Beckett mostram-se não apenas na qualidade e quantidade de suas produções, mas na competência artística com que criou textos literários, peças para teatro, rádio e televisão, e o roteiro de Film de 1965, filmado em Nova York, com direção de Alan Schneider, colaboração de Beckett e atuação principal de Buster Keaton. Além disso, há, claro, suas traduções e, sobretudo, as autotraduções, que o fizeram criar uma obra verdadeiramente bilíngue.

Durante a revisão da tradução de um trecho de Molloy para o inglês, feita pelo escritor sul-africano Patrick Bowles, Beckett resolveu assumir a tradução de seus textos. Justificou sua decisão, em carta de 5 de fevereiro de 1953, para seu editor francês Jérôme Lindon, nestes termos: "De uma maneira geral, sei que não suportarei meu trabalho traduzido para o inglês por mais ninguém. E revisar, com tento fazer agora, causa-me ainda muito mais incômodo que traduzi-lo eu mesmo, e por um resultado lamentável." (BECKETT, 2011, p. 357)

Quando se aborda a prosa de Beckett, é preciso tocar também no interessante fenômeno do escritor bilíngue. Em 1948, ao co- 
meçar a escrever, em francês, os três romances pelos quais sua prosa é mais conhecida - Molloy, Malone morre e $O$ inominável -, Beckett já tinha publicado em inglês um livro de contos (More pricks than kicks, de 1934) e um romance (Murphy, de 1938), além de ter outro romance em inglês inédito, Watt, escrito durante a guerra. A decisão de escrever prosa em francês foi tomada durante a composição da novela $O$ fim em 1945. Coincidentemente, data de 1945 a percepção do escritor sobre o encaminhamento literário que daria à sua obra a partir de então. Trabalharia com a falha, a impotência e a ignorância, colocando-se assim num polo oposto ao de James Joyce, que tendia, segundo Beckett, para a onisciência e a onipotência enquanto artista.

É importante notar que serão alvos da crítica do escritor, em grande parte de sua obra, os níveis mais amplos das linguagens dos próprios gêneros e meios nos quais cria. Igualmente importante é perceber que a prática da autotradução se insere no processo de crítica ao acabado, ao irretocável, pois constitui uma abertura dos textos através de suas versões. Mais tarde, Beckett atingirá um altíssimo grau de depuração com Worstward Ho (1983), no qual a redução da linguagem - no sentido tanto da língua quanto da linguagem narrativa - parece alcançar seu ponto máximo. Ponto em que a restrição de elementos como o lugar, as personagens, e, evidentemente, a própria língua inglesa, reduzida a partículas básicas e variação lexical mínima, se abre para a expressão de algo ainda. A linguagem condensada que produz os fragmentos de pensamentos e imagens de Worstward Ho se incita a ir adiante, organizando-se numa narrativa ainda, a partir do dos seus, para falar com o texto, mais mínimos elementos.

A tradução de Companhia e Outros Textos permitiu-me dar continuidade à tradução de uma parte da prosa de ficção do autor Como é, Molloy e $O$ inominável -, tentando responder não só aos desafios, mas à tarefa-renúncia que essa obra impõe. 


\section{Sobre Companhia, tradução de Company (1980)}

Muitos comentadores da obra de Beckett sublinham o caráter oral da prosa do escritor, com raízes na tradição irlandesa (GONTARSKI, 1995, p. xi-xii). Por mais fragmentárias que sejam suas histórias, o ritmo e os recursos narrativos da voz, ou vozes, que surgem nos textos do autor, são envolventes. O leitor torna-se ouvinte. Em Company, além disso, há uma forte dimensão visual. Se se tratasse de poesia, poderíamos dizer com Erza Pound que o texto é um exemplo de melopéia e logopéia. Talvez venha daí o interesse de tantos encenadores na obra em prosa de Beckett, que tanto escreveu especificamente para o teatro.

Ao mesmo tempo, reconhece-se uma grande dificuldade de encenar esses textos. Há neles complexidades que envolvem todos os elementos básicos da prosa de ficção, como as relações entre narrador, leitor, personagem, as variações espaço-temporais das situações narradas, o cancelamento ou negação do que foi imaginado, a exigir do leitor igualmente retificações na sua apreensão do texto. As frases iniciais de Company podem nos ajudar a compreender essa questão: "A voice comes to one in the dark. Imagine." (BECKETT, 2009a., p. 3). Traduzi assim: "Uma voz chega a alguém no escuro. Imaginar." (BECKETT, 2012, p. 27) Por que, perguntaram alguns leitores, essa escolha de traduzir o imperativo em inglês "Imagine" pelo infinitivo em português? A decisão de traduzir "imagine" por "imaginar" foi tomada a partir da autotradução de Beckett do mesmo trecho para o francês. Cito Beckett, em Compagnie: "Une voix parvient à quelqu'un dans le noir. Imaginer.” (BECKETT, 1989, p. 7)

Em A Tradução como um Outro Original, (SOUZA, 2006) tratei da autotradução de Beckett e das alternativas que ela oferece para os seus tradutores. Sempre usei esse recurso ao traduzir Beckett e defendo seu caráter flexível e criativo. Acrescente-se a isso que em Companhia há um jogo de vozes muito amplo; vozes que não se dirigem apenas ao ouvinte deitado de costas no escuro, mas aludem também ao leitor e ao próprio narrador/criador da 
história, que, de resto, não podemos afirmar com certeza se é um só, dois, ou alguém que se desdobra num outro. Com base nessa indeterminação, preferi usar o infinitivo em português, no seu valor de imperativo impessoal, que dá ao verbo um maior alcance, sem definir a quem se dirige. Dessa forma, o apelo a "imaginar" não está restrito a ninguém, mas envolve todos - leitor, narrador, autor, personagens que ainda vão surgir - em seu comando para começar o jogo ficcional.

Como considerações mais prosaicas estão sempre presentes durante o processo de tradução, convém comentar duas questões bastante específicas que tiveram peso na versão das primeiras palavras de Companhia. Optei por "Imaginar", levando em conta que, em português, tanto o imperativo de segunda pessoa ("imagina") como o de terceira ("imagine"), usado para "você", são empregados coloquialmente de maneira irônica, como se aquilo a que se referem fosse uma mentira ou conversa fiada, como na frase: "Imagina (ou imagine) se dá pra acreditar nisso!”. A outra questão é que o mesmo "imagina" (ou "imagine”), em alguns lugares do Brasil, funciona como equivalente a um "de nada" ou "disponha", quando se agradece a alguém. Os ecos desses empregos coloquiais não seriam bem-vindos. O primeiro porque romperia o pacto que se tenta estabelecer no início do texto com o leitor, e, apesar de Beckett acolher bem a ironia implícita nessa expressão ("Imagine!"), seria introduzida uma conotação alheia à composição. O segundo, por despertar associações ainda mais distantes do teor da narrativa que começa a tomar forma.

Resumindo a ampliação de possibilidades dada pelo infinitivo "Imaginar", também usado como imperativo em nossa língua, vale dizer que a realidade em Companhia é, desde a primeira linha, uma realidade explicitamente imaginada ("Uma voz chega a alguém no escuro. Imaginar.”). Portanto, a sua "verdadeira natureza” é o seu modo de apresentação. Na escolha da voz narrativa de Companhia, o "eu" é interditado, porque o ouvinte não se convence a integrar-se nessa primeira pessoa gramatical. A voz que soa para ele parece originar-se fora desse sujeito sem "eu", a quem ela 
se dirige na segunda pessoa, "você". Outro desdobramento dessa recusa do "eu" materializa-se na presença de um "ele", o "outro pustulento", o "criador", aquele que imagina o "você" para ter companhia. Logo, a voz que surge no texto é composta pela voz do criador, que se utiliza do pronome "ele" para referir-se a si mesmo, e pela voz que chega ao ouvinte e usa o "você" para indicá-lo. É preciso mencionar ainda que o "você" pode muitas vezes referir-se também ao leitor, incluindo-o entre as pessoas do texto. O grau de indeterminação de elementos tão essenciais da narrativa como os que indicam quem fala e quem ouve é fundamental neste texto. Manter uma abertura em relação à pessoa para quem o imperativo de imaginar se dirige também é.

Aqui duas palavras sobre a tradução de duas palavras. Primeiro, "figment", traduzida em francês por "chimère", depois "bourne", em francês, "borne". "Figment" aparece pela primeira vez no final do trecho que se segue àquele em que o criador decidira chamar 0 ouvinte de $\mathrm{M}$ e a si mesmo de W. Cito: "Is there anything to add to this esquisse? His unnamability. Even M must go. So W reminds himself of his creature as so far created. W? But W too is creature. Figment." (BECKETT, 2009a, p. 30)

E em Compagnie: "Reste-il a ajouter à ce croquis. Son innommabilité. Même $\mathrm{M}$ doit sauter. Ainsi W se remémore sa créature telle que créée jusqu'ici. W? Mais lui aussi est créature. Chimère." (BECKETT, 1989, p. 62)

Os dicionários definem "figment" como "something made up or contrived; invented; fabricated". Trazem também a origem latina da palavra: "figmentum", a partir do verbo "fingere" (formar, representar, esculpir, criar). Dão como sinônimos em português "ficção", "invenção", "fantasia". Em Companhia "inventor" e palavras derivadas já tinham sido muito usadas para traduzir diversas passagens onde aparece "deviser" em inglês e "inventeur", em francês; portanto, não quis usar "invenção" para "figment". "Ficção" e "fantasia" pareceram não ser boas alternativas pelo simples fato de haver os vocábulos cognatos em inglês ("fiction" e "fantasy") e estes não terem sido empregados. A opção de traduzir 
do francês e utilizar "quimera" introduziria em português um tom passadista deslocado. Busquei ajuda no fingir do poeta e, apelando para Fernando Pessoa, traduzi assim: "Há algo a acrescentar a esse esboço? Sua inominabilidade. Até M deve ir. Assim W se lembra de sua criatura como até aqui criada. W? Mas W também é criatura. Fingimento." (BECKETT, 2012, p. 51) Mantive esta escolha em todos os outros trechos em que a palavra reaparece. Como apoio a essa opção, cito ainda os seguintes exemplos de um dicionário latino-português (SARAIVA, 2000), no verbete "figmentum": "Figmenta verborum": Palavras forjadas; "Figmenta poetarum": Ficções dos poetas.

A segunda palavra é "bourne". Sua primeira ocorrência em Companhia se dá quando o criador decide rastejar no escuro pelo espaço criado e se frustra ao não encontrar nenhum ponto de onde retornar, seja parede ou muro. Algo que constitua um limite para ele. Cito Company, Compagnie e a minha tradução:

Be that as it may and crawl as he will no bourne as yet. As yet imaginable. Hand knee hand knee as he will. Bourneless dark. (BECKETT, 2009a., p. 32-33)

Quoi qu'il en soit aussi gaillard rampe-t-il aucune borne jusqu'à présent. Genou main genou main. Du noir sans borne. (BECKETT, 1989, p. 68)

Seja como for e rasteje como rastejar nenhum termo até agora. Até agora imaginável. Mão joelho mão joelho à vontade. Escuro sem termo. (BECKETT, 2012, p. 54)

Ao escolher a palavra "termo", tinha em mente a referência de Beckett ao famoso solilóquio de Hamlet na primeira cena do $3^{\circ}$ ato. Mais especificamente ao trecho: "But that the dread of something after death,/The undiscovered country from whose bourne/No traveller returns, puzzles the will". O sentido de "bourne" 
como limite, fronteira, marco divisório fica ainda mais evidente na peça dada a sua proximidade com "country"; "bourne" também significa objetivo ou fim, destinação. Deve-se mencionar que, em ambas as acepções do inglês, se trata de uma palavra já em desuso. Ao escolher "termo", levei em conta os dois significados originais, nos quais está implícita a ideia de "fim", como término, bastante presente em português. Todos esses sentidos comparecem igualmente quando a palavra "bourne" ocorre em Sobressaltos, numa citação muito mais óbvia da fala de Hamlet, em que pude manter a escolha feita em Companhia, justamente por não ter optado por "limite" nem "fim" ("limit", "end"), empregados na mesma frase:

For he could recall no field of grass from even the very heart of which no limit of any kind was to be discovered but always in some quarter or another some end in sight such as a fence or other manner of bourne from which to return. (BECKETT, 2009a., p. 112)

Pois ele não conseguia se lembrar de nenhum campo de relva no coração mesmo do qual nenhum limite de nenhum tipo pudesse ser descoberto mas sempre em algum canto ou outro algum fim à vista como uma cerca ou outra forma de termo do qual retornar. (BECKETT, 2012 , p. 93-94)

\section{Sobre Pra frente o pior, tradução de Worstward Ho}

O início da redação de Worstward Ho está datado de 9 de agosto de 1981 (KNOLWSON, 1996, p. 674) e sua publicação se deu em 1983. Dos textos mais importantes de Beckett, este foi o único que o escritor não traduziu. Depois das primeiras tentativas, perguntou ao amigo, futuro biógrafo, como seria possível traduzir as primeiras palavras ("On. Say on.”) para o francês sem perder sua força (KNOLWSON, 1996, p. 684). Não foi possível. Dois anos depois 
da morte do autor, foi publicada a tradução de Edith Fournier, com o título de Cap au pire, escolhido por Beckett de uma lista que a tradutora lhe apresentara.

Antes mesmo das primeiras palavras, a escolha do título já coloca problemas. Worstward Ho modifica a expressão "westward" (rumo ao oeste), seguida da partícula "ho", uma expressão de entusiasmo e ímpeto, algo como "eia" ou "vamos". Westward Hoe é o título de uma peça de 1607 de Thomas Dekker e John Webster, na qual a expansão da cidade de Londres para o oeste na época era satirizada. $\mathrm{O}$ título refere-se ao grito dos barqueiros do Tâmisa para indicar - usavam também "eastward ho" - a direção em que patiriam. Westward Ho! (1855), por sua vez, intitula um romance histórico de Charles Kingsley, ambientado na era elisabetana, narrando as aventuras de um personagem num navio corsário inglês pelo Caribe. A alteração de "West" para "worst" na expressão consagrada me orientou a buscar em português também uma expressão coloquial para modificá-la, introduzindo o "pior". Com base em frases ufanistas da época da ditadura como "pra frente Brasil”, "este é um país que vai pra frente", e outras mais antigas como "pra frente é que se anda", decidi. A junção do "pra frente" com "o pior" me pareceu funcionar bem como a tradução brasileira de "worstward ho".

As primeiras frases de Worstward Ho colocam o problema básico da tradução de "on", comentada - e evitada - por Beckett. Uma escolha comum aos tradutores de línguas neolatinas é a palavra "ainda". Foi usada em francês ("encore"), espanhol ("aún") e italiano ("ancora"). Diversamente, na tradução portuguesa, empregou-se "em diante”. Escolhi "adiante”, por várias razões. A primeira foi a de manter uma palavra que indicasse uma progressão mais espacial que temporal, que mostrasse o andamento do texto como um impulso de escrita, de um dizer que se move "adiante" na página. Assim no parágrafo inicial, temos: "On. Say on. Be said on. Somehow on. Till nohow on. Said nohow on." (BECKETT, 2009a., p. 81). Fiz a seguinte tradução: “Adiante. Dizer adiante. Ser dito adiante. De algum modo adiante. Até de nenhum modo adiante. Dito de nenhum modo adiante."(BECKETT, 2012, p. 65) 
Embora em termos de concisão haja, como se diz em Como é, perdas por toda parte, as repetições funcionam como meio de manter um esquema aliterativo e assonante em /d/ e /t/ /an/ /en/ e /um/. É claro que a palavra "ainda" também se prestaria à manutenção desses valores sonoros, além de ser mais curta - uma sílaba a menos - e indicar também continuidade, prosseguimento em termos temporais. Neste ponto, o favorecimento de "adiante" ocorreu porque os significados deste advérbio contemplam tanto a conotação temporal ("posteriormente", "mais tarde") como a espacial ("na frente de") e a de prosseguimento, continuidade. Além disso, há seu uso como interjeição, exprimindo "um estímulo, incentivo ou intimação para que se dê prosseguimento a algo que foi interrompido ou está se realizando sem a rapidez necessária”, e, como substantivo, significando "o tempo vindouro, o futuro" (HOUAISS, 2001, p. 83). "Ainda" contempla apenas as conotações temporal e de continuidade. Outro motivo bastante forte para não se usar essa palavra para traduzir "on" foi a perda que isso acarretaria para a tradução de diversas ocorrências de "still" com o significado de "ainda", no texto, especialmente quando é utilizada junto a "on". Por exemplo: "Still dim still on. So long as still dim still somehow on. Anyhow on. (BECKETT, 2009a. , p. 92) Trecho traduzido por: "Ainda penumbra ainda adiante. Até quando ainda penumbra ainda de algum modo adiante. De qualquer modo adiante." (BECKETT, 2012, p. 76)

Vejamos também as traduções de Edith Fournier e de Grabriele Frasca do mesmo trecho, em francês e italiano, respectivamente: "Encore la pénombre alors encore. Aussi longtemps qu'encore la pénombre alors encore tant mal que pis encore. Tant pis que pire encore." (BECKETT, 1989, p. 35); e Frasca: “Allora ancora il fosco ancora. Ancora a condizione che il fosco allora in qualche modo ancora. In ogni modo ancora." (BECKETT, 2008, p. 76-77)

Em francês e em italiano, as soluções envolveram a colocação de um "então" ("alors", "allora") e o uso indistinto do "encore" e do "ancora", que traduziam o "on" para traduzir também o "still". Infelizmente, não conseguimos a tradução espanhola, que 
se encontra esgotada. Temos apenas o artigo de um dos tradutores (foram cinco a realizar a tarefa), Daniel Aguirre-Oteiza, pelo qual sabemos que o "on" foi traduzido por "aún" e, nas ocorrências de "still”, tanto "todavía" quanto "aún" foram utilizados (AGUIRRE-OTEIZA, 2003, p. 47-57).

Worstward Ho é o último de um conjunto de textos que Beckett concordou em reunir num único volume para a edição em língua inglesa, chamado Nohow on. Os outros dois são Companhia e Mal visto mal dito, publicados em 1980 e 1981, respectivamente. Nesses textos aparece cada vez mais a divisa do "mal dizer", também conhecida pelos leitores de Beckett como o "falhar melhor". O filósofo Alain Badiou explica bem, na sua leitura de Worstward Ho, este que é um dos pontos mais comentados da prosa beckettiana. O "dizer mal", segundo Badiou, é intrínseco à condição do dizer em Beckett, o seu imperativo (2002, p. 131). A tão citada busca do fracasso realiza-se numa busca contínua de um dizer que não se subordine ao dito, de um dizer artístico livre e, por causa mesmo desta dupla condição de arte e liberdade, profundamente rigoroso em suas tentativas.

É preciso mencionar que, no início da redação de Worstward $H o$, Beckett tinha em mente as falas sobre o pior de Edgar, na peça King Lear de Shakespeare, sobretudo as seguintes: "O gods! Who is 't can say, 'I am at the worst'? I am worse than e'er I was" e "And worse I may be yet; the worst is not, So long as we can say, "This is the worst'". (Ato IV, cena I).

Em Worstward Ho, a voz é totalmente impessoal, a narrativa se quer oral ("Dizer adiante"), mas é na escrita que prossegue. Tudo é difícil de imaginar e a dificuldade é em si um meio de prosseguimento. Assim: primeiro se tenta imaginar um corpo (uma mente) e o lugar em que se encontra. A partir do lugar, diz-se também a luz. É como se a narrativa saísse dos próprios elementos que a compõem e, claro, da própria língua, submetida ao imperativo do dizer "melhor pior" e do "mínimo". Como exemplo, vejamos a luz que há neste lugar, que é vácuo. Trata-se de uma "luz de penumbra" (“dim light”): “Dim light source unknown. Know minimum. 
Know nothing no. Too much to hope. At most mere minimum. Meremost minimum." (BECKETT, 2009a. , p. 82) Na minha tradução: "Luz de penumbra fonte não sabida. Saber mínimo. Saber nada não. Demais para esperar. No máximo meromínimo. Meromáximo mínimo." (BECKETT, 2012, p. 66)

Para se ter uma ideia de como a tradução de um trecho desses pode ter resultados diferentes, cito a tradução portuguesa de Miguel Esteves Cardoso: "Luz obscura origem desconhecida. Sabe-se o mínimo. Não se saber nada. Seria esperar de mais. Quando muito o mínimo dos mínimos. Maximamente menos que o mínimo dos mínimos." (BECKETT, 1996, p. 9)

Aqui, a par da ideia do pior em contraste, melhor dizendo, complementaridade e, por vezes, equivalência com o melhor, introduz-se a ideia do mínimo e do menos como máximo e mais, e vice-versa. Tudo isso em relação ao tipo de luz, que depois passará a ser referida, por meio do adjetivo substantivado, como "the dim". Foi esse uso que nos levou a traduzi-la como "luz de penumbra" para depois poder indicá-la apenas como "a penumbra" ("the dim").

Antes disso, porém, o lugar que se imagina será descrito como "dim void", que traduzi por "vácuo sombrio", pois o adjetivo "penumbroso" em português não possui nem de longe a coloquialidade de "dim" em inglês. No entanto, o uso de "dim" no texto não se resume a adjetivo e substantivo. Será usado como verbo, depois com prefixo de negação, além de agregar outros modificadores. Então foi aqui onde senti a necessidade de recorrer a mais de uma palavra para a tradução de "dim". Escolhi o adjetivo "sombrio" e os particípios "desemsombrada" e "ensombrada" para, respectivamente, "dim", "undimmed" e "dimmed". A passagem é a seguinte: "So leastward on. So long as dim still. Dim undimmed. Or dimmed to dimmer still. To dimmost dim. Leastmost in dimmost dim. Utmost dim. Leastmost in utmost dim. Unworsenable worst." (BECKETT, 2009a., p. 95) Traduzi-a assim: "Assim pro mínimo adiante. Até quando ainda penumbra. Penumbra desemsombrada. $\mathrm{Ou}$ ensombrada para mais sombria ainda. Para a mais sombria penumbra. Minimáximo na mais sombria penumbra. Penumbra 
máxima. Minimáximo na penumbra máxima. Impiorável pior." (BECKETT, 2012, p. 80)

A tradução de Esteves Cardoso foi: "Menoravante em diante então. Enquanto obscuro ainda. Obscuro inobscurecido. Ou obscurecido até mais obscuro ainda. Até obscuro inobscurecível. Inminorável no obscuro inobscurecível. Máximo obscuro. Inminorável no máximo obscuro. Pior impiorável." (BECKETT, 1996, p. 29)

Como disse no início, há um limite para a justificação das escolhas do tradutor. Mencionei também, na nota que precede as traduções do volume Companhia e outros textos, que Beckett, ao que parece, não quis fazer o "trabalho de luto" a que todo o tradutor deve se submeter, de acordo com a apropriação de Paul Ricoeur dos termos freudianos. Esse "trabalho" corresponde à renúncia a uma tradução perfeita, absoluta (RICOEUR, 2011, p. 48). Praticamente todas as autotraduções beckettianas são lidas assim, como pares perfeitos dos textos "originais" (em francês ou inglês). Mas Beckett preferiu deixar Worstward Ho sem tradução. É possível que, para ele, esta fosse uma composição não apenas escrita em língua inglesa, mas elaborada com e pela própria língua inglesa, desde seus mínimos sentidos e sons. Por não ter dúvidas disso, fiz minha tentativa no sentido de recriar os efeitos sonoros possíveis em português, sobretudo os que nos chegam límpidos pela própria quantidade de repetições das mesmas palavras. Outra meta foi não descuidar do sentido das imagens que o texto produz, tarefa possível não só pela aceitação das perdas, mas também pelas compensações de que o desejo de traduzir se alimenta.

Traduzir, por exemplo, "fail" por "falhar" e não por "fracassar" foi uma escolha muito mais pautada pelo som e pela brevidade da palavra do que por outras considerações. Mesmo assim, levei em conta os significados dicionarizados de ambos os termos, anotando que o primeiro comporta mais nuances de fracasso que o estrepitoso "fracasso" propriamente dito. Mas foram de fato as duas sílabas de "falhar" que resolveram a questão logo no começo do texto, dentro do parágrafo quinto: “Try again. Fail again. Better again. Or better worse. Fail worse again. Still worse again. 
(BECKETT, 2009a. , p. 81) Ficou assim: "Tentar de novo. Falhar de novo. Melhor de novo. Ou melhor pior. Falhar pior de novo. Ainda pior de novo." (BECKETT, 2012, p. 66)

Os textos finais de Samuel Beckett exigem do leitor uma atenção redobrada, uma leitura lenta, talvez em voz alta. Apesar de toda a resistência que impõem, significam pelos sons e imagens que criam. E narram ainda, conduzindo a literatura no seu "melhor pior" adiante.

\section{Referências}

AGUIRRE-OTEIZA, Daniel. Traducir aún: notas sobre la traducción de Worstward Ho de Samuel Beckett. Vasos Comunicantes: Revista da ACE Traductores, n. 26, p.47-57, 2003. Disponível em: http://revistavasoscomunicantes.blogspot. com.br/2011/03/vasos-comunicantes-numero-26.html. Acesso em 14 no. 2013

BADIOU, Alain. Ser, Existência, Pensamento: Prosa e Conceito. In: Pequeno Manual de Inestética. Trad. Marina Appenzeller. São Paulo: Estação Liberdade, 2002. p. 117-162.

BECKETT, Samuel. Como é. Trad. Ana Helena Souza. São Paulo: Iluminuras, 2003.

. Compagnie. Paris: Les Éditions de Minuit, 1989.

. Companhia e outros textos. Trad. Ana Helena Souza. São Paulo: Globo, 2012.

. Company etc. Edited by Dirk Van Hulle. Faber \&Faber: London, 2009a.

. In nessun modo ancora. Trad. Gabriele Frasca. Turim: Einaudi, 2008

Cad. Trad., Florianópolis, n $^{0}$ 34, p. 085-100, jul./dez. 2014 
. Molloy. Trad. Autor. São Paulo: Globo, 2007.

. O inominável. Trad. Autor. São Paulo: Globo, 2009 b.

. The Letters of Samuel Beckett 1941-1956. Cambridge: Cambridge University Press, 2011.

. Últimos trabalhos de Samuel Beckett. Trad. Miguel Esteves Cardoso. Lisboa: Assírio \& Alvim, 1996.

FRASCA, Gabriele. Prefazione. In: Beckett, Samuel. In nessun modo ancora. Trad. Gabriele Frasca. Turim: Einaudi, 2008. p. V-XXX.

GONTARSKI, S. E. Introduction. In: Beckett, Samuel. The Complete Short Prose 1929-1989. New York: Grove Press, 1995. p. xi-xxxii.

HOUAISS, Antônio; VILLAR, Mauro de Salles. Dicionário Houaiss da Lingua Portuguesa. Objetiva: Rio de Janeiro, 2001.

KALB, Johnathan. Beckett in performance. New York: Cambridge University Press, 1989.

KNOLWSON, James. Damned to Fame. The Life of Samuel Beckett. London: Bloomsbury, 1996.

RICOEUR, Paul. Sobre a tradução. Trad. Patrícia Lavelle. Belo Horizonte: Editora da UMFG, 2011.

SARAIVA, F. R. dos Santos. Dicionário Latino-Português. $11^{\text {a }}$. ed. Rio de Janeiro: Livraria Garnier, 2000.

SOUZA, Ana Helena Barbosa Bezerra de. A tradução como um outro original: Como é de Samuel Beckett. Rio de Janeiro: 7Letras, 2006.

Recebido: 05-03-14

Aceito: 10-06-14 